\title{
Building a Ceramic Engine: Applying Science \& Technology to a Design and Research Problem
}

The following is a condensed version of an article written when the authors all were students at Oak Park and River Forest High School in Oak Park, Illinois. The article appeared originally in TIES Magazine, a journal covering technology, materials science, and design for science educators at all levels.

Teachers often tell us that science literacy is on the decline and that there is a shortage of competent scientists and engineers. However, when students express an interest that is above and beyond the norm of the curriculum, those very same teachers have been known to reply:

"It is a very fascinating idea, but we don't have the time or resources to do that," or "That is something you will do in college or graduate school."

These responses occur far too often, especially in science classes, and constitute a serious problem. High school students, unsure of themselves and their futures, need hands-on experiences to become familiar with methods of research, not only to learn science but to evaluate college options and explore career interests. If students are expected to identify a major and make career plans at the age of 17 or 18 , something needs to be done in school to help acquaint them with their options.

Fortunately, situations like the one described above are being remedied in our school. At Oak Park and River Forest High School, we are given opportunities for hands-on, discovery-based learning through two unique classes, titled Technology of Chemistry and Technology of Physics. These classes allow us to try to satisfy our interest in science by conducting independent research. We would like to describe our own participation in these classes, namely, the investigation techniques we used and how they increased our understanding of science and technology.

\section{Gearing Up For Research}

As upper classmen, we had a certain amount of freedom in choosing our classes and schedules. Most of our graduation requirements were completed and our class schedules provided a few extra "free" periods. Robert Gauger, head of the Technology Department, had approached us the previous year with the idea of forming a research team and undertaking an independent study project. We selected the study of ceramics. We knew that many new uses were being discovered for ce- ramics and that it would be an important material in the future.

Ceramic engineering is a broad field, so we needed to limit our investigation to one specific application of ceramics. Our school librarian helped us locate magazine articles and books on current research and developments in this field. Many articles explained how ceramics are being used in high-tech applications. The thermal tiles on the space shuttle orbiter are made from ceramics. Ceramics are the primary compounds being investigated in the field of high-temperature superconductivity. We discovered also that ceramic components were being substituted for some of the parts in internal combustion engines to raise thermal efficiency. This practical application caught our interest. We were excited by the idea that research of this kind could lead to improvements that would increase the overall efficiency of the automobile. After learning about the general properties of ceramics and engine operation, we decided to see for ourselves the effects ceramic coatings have on the efficiency of an internal combustion engine. We started with a basic and practical question: Could we as high school students find the means and resources to build a ceramic engine and test its efficiency? We made inquiries to companies and universities that had access to the ceramic materials critical to this experiment. Prof. Sherman Brown of the Department of Materials Science and Engineering at the University of Illinois at Urbana-Champaign agreed to help us with the project and provide the necessary ceramic technology. Dr. Brown supported our research because he recognized that this investigation, conducted by high school students, was an original and unique study in ceramic engineering.

\section{The Hypothesis}

The purpose of our Ceramic Engineering Project was to test the hypothesis that insulating critical parts of a single-piston internal combustion engine with a ceramic coating will improve the thermal, mechanical, and fuel efficiency of the engine. An internal combustion engine is a heat engine that converts fuel into mechanical force. The four-stroke-cycle internal combustion engine requires four events to complete its task: the intake stroke, the compression stroke, the power stroke, and the exhaust stroke. These cycles create rotational motion that can be measured in terms of horsepower and torque.

During normal operation, an internal combustion engine will lose about 30 percent of the combustion heat to exhaust and an additional 30 percent to the cooling system. Due to the insulating properties of ceramics, we expected that more heat would be trapped inside the engine's combustion chamber, resulting in higher temperatures. Charles' Law states that an increase in temperature causes an increase in pressure. Higher combustion pressure applies greater force to the piston during the power stroke. The addition of ceramic coatings to critical engine parts, therefore, should directly increase horsepower and torque.

\section{Methods And Materials}

Unlike a typical science classroom where the activities are prescribed by the teacher, we had to write our own instructions and parameters. We developed a procedure, considered experimental controls, and determined the exact data that needed to be collected. We systematically answered the four questions of basic scientific testing: what, when, why, and how. We began to practice what scientists and researchers experience when they design and conduct scientific investigations.

The first and most critical step in the research process is selecting a structured testing method. The most important measurement needed to test our hypothesis was the temperature of the exhaust gas. An increase in exhaust gas temperature directly relates to an increase in the temperature of the combustion gas. Therefore, such an increase would verify the effectiveness of the ceramic coating. To observe the engine's fuel and mechanical efficiency, it was necessary to measure horsepower, torque, fuel consumption, and the cylinder head temperature.

Two essential pieces of equipment were needed to conduct the experiment: a four cycle, single-piston gasoline engine, and a dynamometer, which measures the engine's torque and horsepower. Thermometers and timers were also needed to collect our data. As a team, we agreed that engine oil temperature, emissions, and barometric pressure should be monitored as experimental controls. We were able to use an automotive exhaust gas analyzer to monitor levels of carbon monoxide and hydrocarbons during our testing.

Now that we knew what measurements 
were needed to test the theory, we designed a method to collect information. We determined that a static and a dynamic test sequence would provide the needed engine data. The static test analyzed the engine's performance under no-load conditions. Fuel consumption and thermal data were collected. The dynamic test measured engine performance under actual operating conditions. The data from this test sequence were used to calculate torque and horsepower. In all, three sets of data were collected and averaged for the static and dynamic tests.

After the tests on the control engine were completed, the engine was disassembled. The intake and exhaust valves, the piston, and the cylinder head were sent to the Ceramics Division at the University of Illinois where ceramic technicians applied a ceramic cc ating. Zirconium oxide, a ceramic with high thermal insulating properties, was applied to each part, using plasma-arc spray technology. When the parts were returned, we reassembled the engine and repeated the tests.

\section{Data Analysis}

In order to properly analyze the data, we needed to present organized tables and graphs. Using computer graphic software, we expressed the thermal, mechanical, fuel consumption, and emission studies in graphic form. Then the data needed to be tested for significance. After consulting various resources in statistical analysis, we decided to use a computation known as the Student-T test. By using the range and distribution of numbers, the Student-T test mathematically compares the pre- and post-test data and evaluates their significance.

In summary, our analysis of the data strongly supported the validity of our initial hypothesis. The data on the ceramiccoated engine showed no significant increase in fuel consumption, although horsepower increased-a good indication of an increase in engine efficiency. Our analysis showed no significant increase in exhaust gas pollutants produced by the ceramic engine. The most impressive indication supporting our hypothesis was the $62^{\circ}$ Celsius increase in average exhaust temperature for the ceramic engine. The Student-T test yielded results of valid significance, showing that ceramics' high thermal insulating properties are effective in raising the thermal efficiency of the internal combustion engine.

\section{Students' Point of View: \\ Our Personal Insight}

We were surprised by the knowledge and experience we gained from this project. In the short span of nine months (five days a week, one free period a day), we had explored physics, environmental science, computer graphics, word processing, statistics, gas laws, thermodynamics, and materials science. We probably won't ever forget the properties of ceramics, Charles' Law, or how an internal combustion engine works; but if you were to ask us to recite Einstein's Theory of Relativity, you could expect a blank stare in reply.

It seems clear from our experience that people learn best when they learn by doing. Theory and memorization are not as important as the process itself. This project taught us the true meaning of trialand-error in research. We discovered that everything doesn't always work the first time. Often, we took the wrong path or came up with an idea that didn't succeed. But we revised our methods and continued the process. Compare this with what we might have learned in a traditional lec ture course

Doing this project left us better prepared to face our future. As juniors and seniors in high school, we were all experiencing anxiety and fear over college and career choices. It seemed to us that we were expected to know exactly what our future goals were. Many students make plans to study business, teaching, law, medicine, or engineering with little background on which to base their decisions. We discovered firsthand that no matter how much you read about science and technology, you don't know what research is until you do it!

Most importantly, we formed ties that are going to last. Our group effort helped us realize our strengths and differences and taught us to work as individuals, yet as part of a team. We've formed friendships based on hard work, reward, satisfaction, and, of course, FUN. A year ago, we were given the opportunity to learn about science and research firsthand. That opportunity provided a rewarding and enriching experience that we'll never forget.

\section{ELIZABETH BROWN, CHEN TAN, and AKI YOSHIKANE}

Elizabeth Brown is now attending Washington University, where her area of study is pre-medicine, with interests in computer scicho' and physics.

Chen Tan is a senior at Oak Park and Rizer Forest High School. She is continuing the $\mathrm{w}^{-}$ search described here, using three engines and new methods for applying the ceramics.

Aki Yoshikane is now attending Northwestern University, where she is studying engineering.

Robert Gauger is Department Hoad of Technology, Oak Park and River Forest High School, Oak Park, Illinois, and a member of the National Council on Science and Technology Education, American Association for the Advancement of Science, Washington, DC.

\section{SPECIAL NOTICE TO MRS MEMBERS:}

\author{
1993 Members of the Materials Research Society may subscribe to \\ MATERIALS LETTERS for the special rate of $\$ 38$. You will receive \\ Volumes 15, 16, 17 and 18.
}

MATERIALS LETTERS is an interdisciplinary journal affiliated with the Materials Research Society, devoted to the rapid publication of short communications on the science, applications and processing of materials.

$$
\begin{aligned}
& \text { Order your subscription today from: } \\
& \text { Materials Research Society, 9800 McKnight Road, Pittsburgh, PA } 15237 \\
& \text { Phone: (412) 367-3003; FAX: (412) 367-4373 }
\end{aligned}
$$

The Education Exchange highlights the experiences of scientists and engineers with local schools, along with helpful hints and resources. If you would like to share your own involvement in science education, contact Finley Shapiro, Department of Electrical and Computer Engineering, Drexel University, Philadelphia, PA 19104, U.S.A.; telephone (215) 895-6749; Fax (215) 895-1695; Email: shapiro@ece.drexel.edu

To receive additional information on how you can get involved in enhancing K-12 science education, circle number 120 on the Reader Service Card. 


\section{COMPUTATIONAL MATERIALS SCIENCE}

Editors:

U. Landman,

School of Physics, Georgia Institute of Technology, Atlanta, GA 30332, USA

R.M. Nleminen,

Laboratory of Physics, Helsinki Institute of Technology, 02150 Espoo, Finland

COMPUTATIONAL MATERIALS SCIENCE aims to enhance the communication between experimental materials research and computational work on both existing and new, advanced materials and their applications. It publishes articles of interest to physicists, chemists and materials researchers and engineers and to other scientists involved with materials phenomena and computational modelling.

The journal invites contributions on numerical studies and simulations of all properties of materials, including electronic, dynamical, transport, mechanical, growth and thermodynamical properties.

Systems and materials of interest include bulk, surface, interface and defect properties of metals, alloys, semiconductors, insulators, superconductors, biomaterials, polymers, ceramics and composites in different phases of aggregation: liquid, crystal, amorphous, semicrystalline and clusters.

The scope of the journal covers computational modelling of materials properties and phenomena, ranging from the synthesis, characterisation and processing of materials, structures and devices to the numerical methodology of materials simulations.

\author{
Video Library \\ For articles with accompanying videos \\ supplementing and illustrating the research \\ of the editors. \\ Subscription Information: \\ 1992-1993 : Volume 1 (in 4 issues) \\ Price: US $\$ 222.00 /$ Dfl. 368.00 \\ including postage and handling costs \\ ISSN 0927-0256
} described, the videos can be ordered from one

The first issue will appear in the Fall of 1992.

The Dutch Guilder (Dfl.) price is definitive.

US \$ price is subject to exchange rate fluctuations.

\section{COMPUTATIONAL MATERIALS SCIENCE}

$\square$ Please send me a free sample copy

$\square$ Please enter my subscription for 1993 and send me an invoice

\section{Address:}

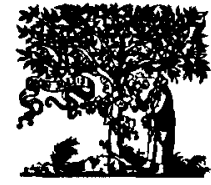

Send this coupon or a photocopy to:

\section{ELSEVIER SCIENCE PUBLISHERS}

P.O. Box 103, 1000 AC Amsterdam, The Netherlands

P.O. Box 945, Madison Square Station, New York, NY 10160-0757 